\title{
Septicemia, malformaciones $y$ recuperación posquirúrgica en ejemplares de Crocodylus acutus en cautiverio.
}

\section{Carta al Editor}

Armando Rubio-Delgado, Fabio G. Cupul-Magaña, Helios Hernández-Hurtado, Abraham Reyes-Juaréz.

Departamento de Ciencias, Centro Universitario de la Costa, Universidad de Guadalajara. Puerto Vallarta, Jalisco, México.

Se reportan cinco casos clínicos observados en ejemplares juveniles de cocodrilo de río, Crocodylus acutus, en cautiverio dentro de las instalaciones de la Unidad para la Conservación, Manejo y Aprovechamiento Sustentable de la Vida Silvestre (UMA) "Reptilario Cipactli”" (clave INE/ CITES/DGVS-CR-IN-0610-JAL./00) dependiente del Centro Universitario de la Costa y cuyo único fin es proporcionar un espacio viable para la protección, reproducción y cuidados veterinarios del cocodrilo de río en la región de la costa sur y norte de los estados de Nayarit y Jalisco, respectivamente.

El primer caso se presentó en un individuo juvenil macho de aproximadamente 3 años de edad, con longitud total del cuerpo de $63 \mathrm{~cm}$ y peso de $1.100 \mathrm{~kg}$. El ejemplar fue decomisado a un particular por la Procuraduría Federal de Protección al Ambiente (PROFEPA) y dado en depositaría a la UMA. Al transcurrir cuatro meses de su ingreso al reptilario, se le detectó una escoriación en la piel, a la altura del segundo tercio ventral de la cauda, por lo que ese mismo día fue separado del grupo y puesto en cuarentena para aplicarle tratamiento preventivo y tomarle una biopsia del tejido dañado para realizar un cultivo bacteriológico y micológico.

El tratamiento consistió en la administración intramuscular de Amikacina 2.25 mg/kg y $10 \mathrm{cc} /$ $\mathrm{kg}$ intracelómica de solución Hartmann como hidratante, repitiendo $1.75 \mathrm{mg} / \mathrm{kg}$ de Amikacina a las 96 horas, completando cinco tratamientos. Por otra parte, se administraron $30 \mathrm{mg} / \mathrm{kg}$ vía oral de Ketoconazole cada 24 horas.

Asimismo, el cultivo bacteriológico evidenció la presencia de Proteus vulgaris (+++), Escherichia coli (+) y Staphilococcus aureus (+), microorganismos sensibles, en orden de proporción, al aminoglucósido Amikacina aplicado al cocodrilo. Por su parte, el cultivo micológico manifestó la presencia de los hongos Trichophyton tonsurans y Candida albicans, ambos sensibles al Ketoconazole suministrado.

A pesar de que el cocodrilo mostró cierta mejoría en las escoriaciones, le fue descubierta atrofia muscular en la extremidad posterior

Solicitud de sobretiros: M. en C. Fabio G. Cupul-Magaña, Depto. de Ciencias, Centro Universitario de la Costa, Universidad de Guadalajara, Av. Universidad de Guadalajara No 203, Deleg. Ixtapa, C.P. 48280, Puerto Vallarta, Jalisco, México. Correo electrónico: fcupul@pv.udg.mx Recibido el 16/Enero/2001. Aceptado para publicación el 19/Enero/2001. 


\section{A Rubio-Delgado, FG Cupul-Magaña, H Hernández-Hurtado, A Reyes-Juaréz.}

izquierda. Para el $1^{\circ}$ de noviembre del 2000 el organismo falleció.

La necropsia reveló el inicio de necrosis hemorrágica en riñones por posible septicemia. El resto de los tejidos se encontraron aparentemente normales.

Un aspecto importante a resaltar fue la presencia en el estómago de una alta cantidad de gastrolitos con diámetros entre 1 y $15 \mathrm{~mm}$, los cuales sumaron un peso de $58 \mathrm{~g}$, correspondiendo al $5.27 \%$ del peso corporal del animal. Esta proporción supera a la más alta registrada en cocodrilos hasta la fecha de $4.15 \%$ del peso corporal en un ejemplar de Crocodylus palustris en la India (1). La necropsia también mostró la ausencia de contenido gástrico en los intestinos, posiblemente como resultado de la obstrucción generada por la alta cantidad de gastrolitos, que aunado al proceso infeccioso, contribuyó al deceso del individuo tal y como ha sido observado en otras especies de cocodrilos (1) y cuya ocurrencia y función dentro de sus estómagos aún no ha sido aceptablemente aclarada (2).

Por otro lado, los siguientes tres casos son reportes de malformaciones observadas en ejemplares juveniles de cocodrilo de río provenientes de un nido silvestre que se incubó artificialmente en el criadero de la Secretaría de Medio Ambiente y Recursos Naturales

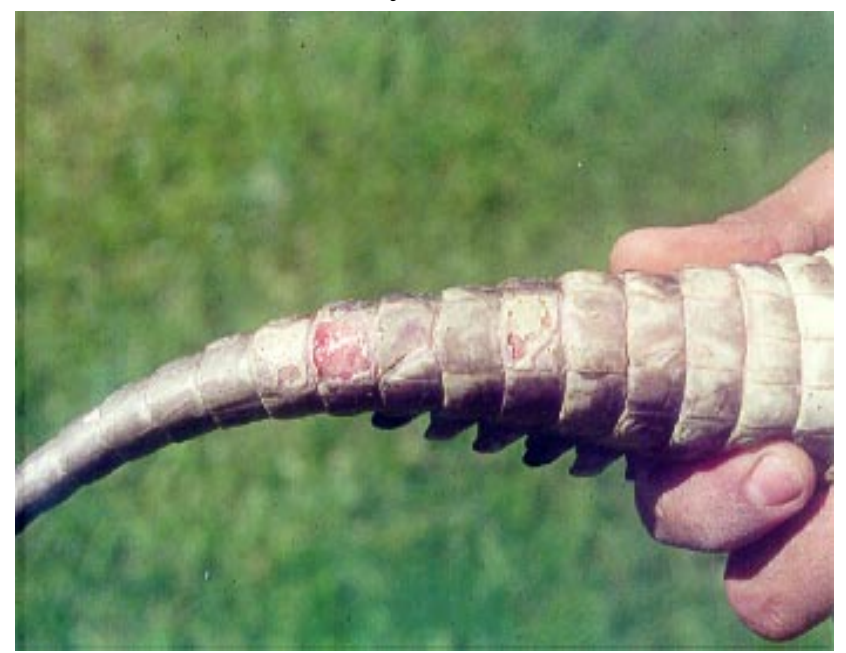

Figura 1.- Lesión por micosis observada a la altura del segundo tercio ventral de la cola de juvenil de cocodrilo de río en cautiverio.

Revista Biomédica
(SEMARNAT), ubicado en la localidad de Platanitos, Municipio de San Blas, Nayarit. Los tres ejemplares, de 3 años de edad y sexos indeterminados, fueron dados por la Secretaría en depositaría en custodia a la UMA, ya que no pudieron ser liberados al medio silvestre por sus impedimentos físicos. Dos de ellos, con longitudes totales de 72 y $65.3 \mathrm{~cm}$, presentan una hipotrofia bilateral en órbitas oculares (son ciegos) y el tercero, con longitud total de $59 \mathrm{~cm}$, sufre de una distrofia muscular y ósea degenerativa a partir de la quinta vértebra lumbar. Los registros de defectos de nacimiento en cocodrilos, hablan de éstos como malformaciones espontáneas atribuibles a deficiencias en la dieta de la madre, incubaciones fuera de los límites de temperatura viable, consanguinidad, traumatismo provocado en el cascarón en su manipulación, agentes patógenos o prácticamente defecto genético (3). La mayoría de las malformaciones son fatales para el recién nacido, más en nuestro caso, la evolución de los ejemplares ha sido satisfactoria, no requiriendo de la asistencia humana para su alimentación o actividades diarias en cautiverio.

Por último, en el volumen 11, número 3 de la Revista Biomédica (4), se describió la primera cirugía ortopédica reconstructiva unilateral de maxilar inferior realizada en México a un ejemplar juvenil macho de Crocodylus acutus. La placa ortopédica y el cerclaje se retiraron

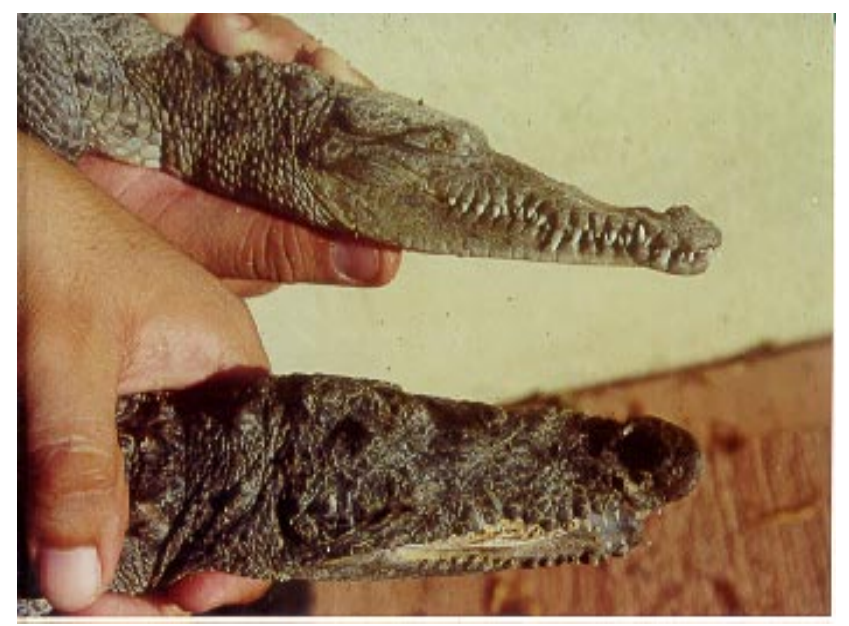

Figura 2.- Vista lateral y distal de juveniles de cocodrilo de río con hipotrofia bilateral en órbitas oculares. 


\section{Casos clínicos de Crocodylus acutus en cautiverio.}

anticipadamente al mes y medio de colocados, porque el cocodrilo los aflojó, pero se logró que se uniera parte de la mandíbula fracturada. Durante las siguientes semanas se retiraron algunas astillas de hueso.

A casi once meses de la intervención quirúrgica, el organismo mejoró en un $75 \%$ la funcionalidad de la mandíbula. Actualmente el cocodrilo se alimenta de manera independiente, aunque fue necesaria su alimentación forzada durante los dos meses y medio posteriores a la operación. El tejido en la zona reconstruida se

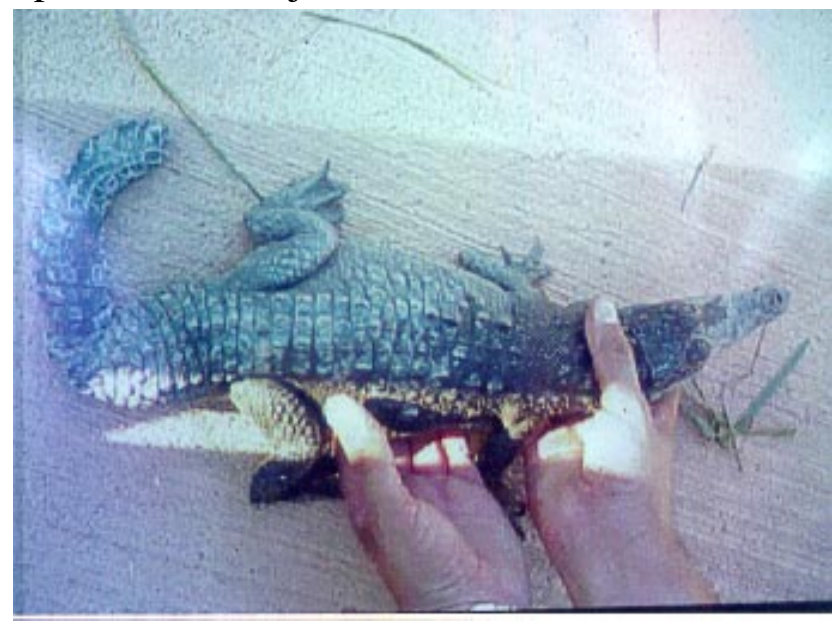

Figura 3.- Ejemplar de cocodrilo de río juvenil con distrofia muscular y ósea degenerativa a partir de la quinta vértebra lumbar.

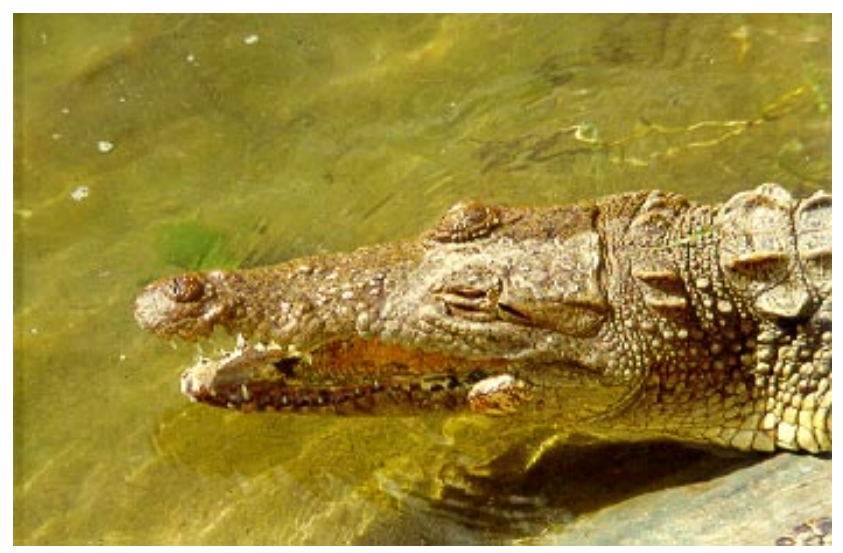

Figura 4.- A once meses de realizada la cirugía ortopédica en un ejemplar juvenil de cocodrilo de río, la fotografía muestra la zona regenerada en un $90 \%$ (cerca de la base de la mandíbula inferior), situación que finalmente provocó un acortamiento de la mandíbula inferior y su desviación, de aproximadamente cinco grados a la izquierda, con respecto a la mandíbula superior. regeneró en un $90 \%$, lo que finalmente provocó un acortamiento de la mandíbula inferior y su desviación, de aproximadamente cinco grados a la izquierda, con respecto a la mandíbula superior. Desafortunadamente el ojo izquierdo que le fue dañado al causarle la fractura, sólo se recuperó en un $50 \%$. Se puede concluir que la adaptación del organismo y el éxito de la cirugía fue del $100 \%$, tanto así que en sus once meses de cautiverio el organismo ha aumentado $1.350 \mathrm{~kg}$ en peso (de 3.850 a $5.200 \mathrm{~kg}$ ) y $9 \mathrm{~cm}$ en longitud total (de 1.05 a $1.14 \mathrm{~m})$.

Con el reporte de estos casos, se busca contribuir al conocimiento sobre el manejo veterinario del cocodrilo de río en cautiverio.

Palabras clave: Crocodylus acutus, septicemia, malformaciones, cirugía ortopédica, gastrolitos.

\section{REFERENCIAS.}

1.- Whitaker N. Excessive stomach stones in an indian mugger. Crocodile Specialist Group Newsletter 2000; 19 (Supl 2): 20.

2.- Ross F. Stomach stones. Crocodile Specialist Group Newsletter 2000; 19 (Supl 2): 20.

3.- Ferguson MWJ. Birth defects in american alligators. En: Ross CA, Garnett S, editores. Crocodiles and Alligators. New York: Facts on File; 1989. p. 98.

4.- Rubio-Delgado A, Hernández-Hurtado H, Maraña-Peña V, Aguilar del Portillo FJ, Cupul-Magaña FG, EstradaDurán G. Cirugía ortopédica reconstructiva unilateral de maxilar inferior en un ejemplar juvenil de Crocodylus acutus: reporte de caso. Rev Biomed 2000; 11:213-4. 